\title{
Sliding mode control design of wind power generation system based on permanent magnet synchronous generator
}

\author{
Nada Zine Laabidine, Afrae Errarhout, Chakib El Bakkali, Karim Mohammed, Badre Bossoufi \\ LIMAS Laboratory, Faculty of Sciences Dhar El Mahraz, Sidi Mohamed Ben Abdellah University, Fez, Morocco
}

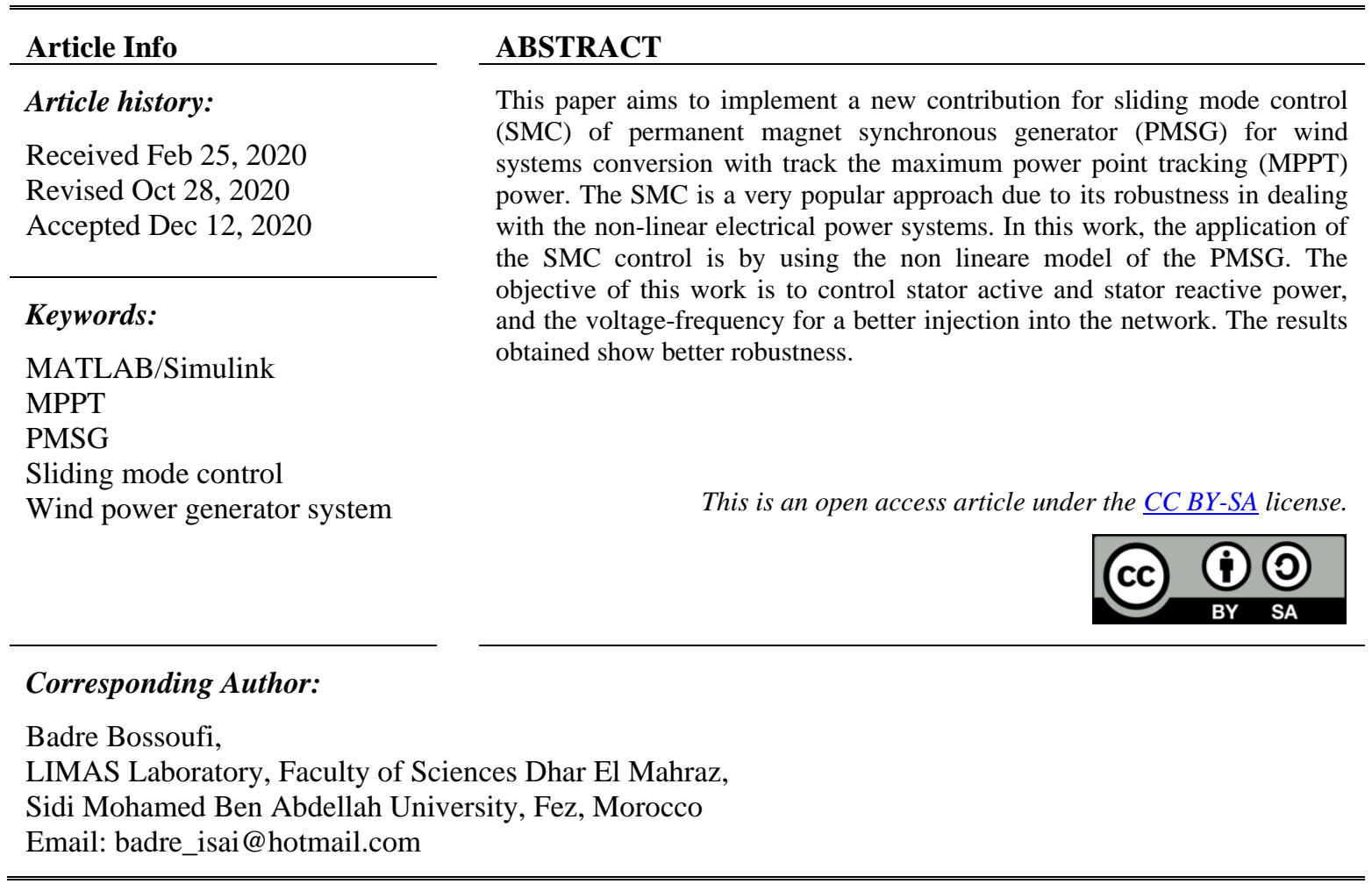

\section{INTRODUCTION}

Lately, the use of renewable energies (i.e., wind and solar photovoltaic) to increase in an incredible way thanks to the scarcity of combustibles. Wind energy is supposed to be the best in terms of quality and price.

There are several research studies about the wind turbine. In particular, the ones with asynchronous generators. Although, they have a low cost and simple maintenance as advantage but, they require more expensive equipment and complex control. Therefore, in the recent years, the Wind turbine System moved towards the permanent magnet synchronous generator (PMSM) machine which has higher quality and larger power density. Furthermore, the permanent magnet synchronous generator (PMSG) reduces the mechanical stress by removing the necessity of the multiplicator which improves the system's reliability and decreases the maintenance costs by directly coupling the turbine and the shafts of the generator [1]-[16].

Due to the high variability of the speed, it's difficult to get satisfactory systems of wind turbine system. Recently, this latter is grab to extract the maximum power point (MPP) from the wind speed, which represent the maximum power point tracking (MPPT) strategy. Different methods have been his goal is to fix operating point of maximum efficiency. The most widespread control strategy is the optimum power/torque tracking, where the use of the PI controller. This technique alone doesn't realize a better performance. Hence, there are also other control strategies such as the backstepping and direct power control (DPC) [2].

This work is repatriated as: section 2 presents the description of the wind system (turbine, PMSG, inverter, DC-bus, and filter). Section 3 discusses the principle of operation of the sliding mode command as well as its application on our system. Section 4 shows and interprets the results of the simulation. Finally, a conclusion. 


\section{MODELLING OF WIND TURBINS}

The system to control in this work is a PMSG-based wind system. Figure 1 presents the different components of the system [3]-[17]

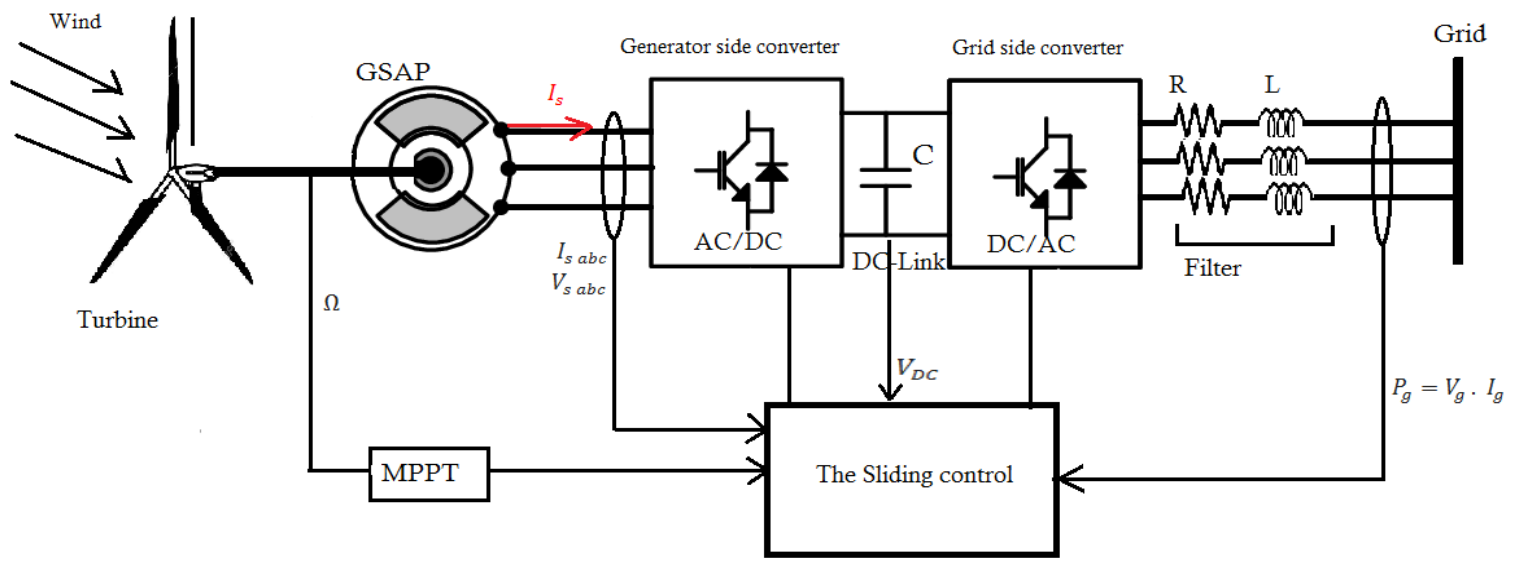

Figure 1. SMC Control for the WECS

\subsection{The model of wind turbine}

The model of wind turbine is [4]:

$$
\begin{aligned}
& P_{\text {wind }}=\frac{\rho S V^{3}}{2} \\
& P_{\text {tur }}=\frac{\rho \pi R^{2} V^{3} C_{P}(\lambda, \beta)}{2} \\
& C_{P}=\frac{P_{\text {tur }}}{P_{\text {wind }}} \\
& \lambda=\frac{R \omega}{V} \\
& \left\{\begin{array}{c}
P_{\text {tur }}=\omega \cdot T_{\text {tur }} \\
T_{\text {tur }}=\frac{1}{2}\left[\rho \pi R^{3} V^{2} C_{P}(\lambda, \beta)\right]
\end{array}\right. \\
& \left\{\begin{array}{c}
T_{\text {tur_opt }}=K \omega^{2} \\
K=\frac{1}{2}\left[\rho \pi R^{5} C_{P-\max }\left(\lambda_{\text {opt }}\right)\right]
\end{array}\right.
\end{aligned}
$$

$\lambda_{\text {opt }}$ optimal specific speed.

With:

$P_{t u r}$, the output power.

$T_{\text {tur_opt }}$, the optimal turbine torque.

$T_{t u r}$, the turbine torque.

$C_{p}$, the power coefficient.

$S$, the blade swept area.

$R$, the radius of the blade.

$\rho$, air density.

\subsection{The model of PSMG}

The PMSM equations are presented as following [5]:

- Stator voltages: 


$$
\left\{\begin{array}{l}
V_{s d}=R_{S} \cdot I_{s d}+\frac{d \psi_{d}}{d t}-\omega_{r} \cdot \psi_{q} \\
V_{s q}=R_{S} \cdot I_{s q}+\frac{d \psi_{q}}{d t}+\omega_{r} \cdot \psi_{d}
\end{array}\right.
$$

- $\quad$ Stator flux:

$$
\left\{\begin{array}{c}
\psi_{d}=L_{d} \cdot I_{s d}+\Phi_{f} \\
\psi_{q}=L_{q} \cdot I_{s q}
\end{array}\right.
$$

From (7) and (8) the stator voltages can be written as [6]-[18]:

$$
\left\{\begin{array}{c}
V_{s d}=R_{S} \cdot I_{s d}+L_{d} \frac{d I_{s d}}{d t}-\omega_{r} \cdot L_{q} \cdot I_{s q} \\
V_{s q}=R_{S} \cdot I_{s q}+L_{q} \frac{d I_{s q}}{d t}+\omega_{r} \cdot L_{d} \cdot I_{s d}+\omega_{r} \cdot \Phi_{f}
\end{array}\right.
$$

The electromagnetic torque is defined:

$$
\left\{\begin{array}{c}
T_{t u r}-T_{e m}=J \cdot \frac{d \Omega}{d t}+f_{C} \cdot \Omega \\
T_{e m}=\frac{3}{2} \cdot p\left[\left(L_{d}-L_{q}\right) I_{s d} \cdot I_{s q}+I_{s q} \cdot \Phi_{f}\right]
\end{array}\right.
$$

The power for PMSM is:

$$
\left\{\begin{array}{l}
P_{g e n}=\frac{3}{2}\left[V_{s d} I_{s d}+V_{s q} I_{s q}\right] \\
Q_{g e n}=\frac{3}{2}\left[V_{s q} I_{s d}-V_{s d} I_{s q}\right]
\end{array}\right.
$$

\subsection{Model of converters}

To connect the generator which undergoes a variable speed with the network, it is necessary to go through a stage of power electronics in order to control the power injected. we use 2 RSC and GSC conversion stages, converters which consists of IGBTs as shown in Figure 2 [7]-[19].

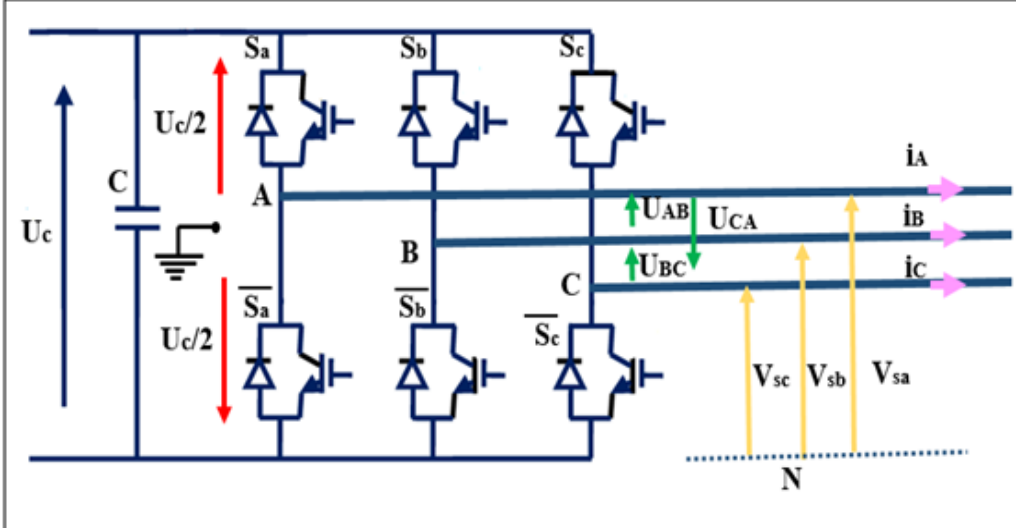

Figure 2. Converter Model

$$
S=\left\{\begin{array}{l}
+1, \bar{S}=-I \\
-1, \bar{S}=+I
\end{array}, S=a, b, c\right.
$$

The input voltages between phases of the converter can be described by: 


$$
\left\{\begin{array}{l}
U_{A B}=V_{A O}-V_{B O} \\
U_{B C}=V_{B O}-V_{C O} \\
U_{C A}=V_{C O}-V_{A O}
\end{array}\right.
$$

At the load level, the simple voltages are expressed by:

$$
\left\{\begin{array}{l}
U_{A B}=V_{A}-V_{B} \\
U_{B C}=V_{B}-V_{C} \\
U_{C A}=V_{C}-V_{A}
\end{array}\right.
$$

We can deduce the matrix form of the simple tensions:

$$
\left[\begin{array}{l}
V_{A} \\
V_{B} \\
V_{C}
\end{array}\right]=\frac{1}{3}\left[\begin{array}{ccc}
2 & -1 & -1 \\
-1 & 2 & -1 \\
-1 & -1 & 2
\end{array}\right]\left[\begin{array}{l}
V_{A O} \\
V_{B O} \\
V_{C O}
\end{array}\right]
$$

With $\left[\begin{array}{l}v_{A O} \\ v_{B O} \\ v_{C O}\end{array}\right]=\frac{U_{C C}}{2}\left[\begin{array}{l}S_{A} \\ S_{B} \\ S_{C}\end{array}\right]$

$$
\left[\begin{array}{l}
v_{A} \\
v_{B} \\
v_{C}
\end{array}\right]=\frac{U_{C C}}{6}\left[\begin{array}{ccc}
2 & -1 & -1 \\
-1 & 2 & -1 \\
-1 & -1 & 2
\end{array}\right]\left[\begin{array}{l}
S_{A} \\
S_{B} \\
S_{C}
\end{array}\right]
$$

\subsection{Model of DC bus}

The DC bus allows the transfer of power between two different frequency sources; it is used to connect the two converters of the wind system to each other as shown in Figure 3 [8]-[20].

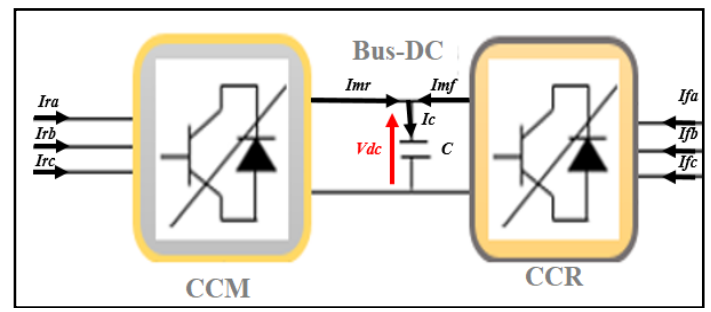

Figure 3. DC-Bus Model

The equations for the DC bus are:

$$
\left\{\begin{array}{c}
W_{d c}=\int P_{c} \cdot d t=\frac{1}{2} \cdot C \cdot V_{d c}^{2} \\
\frac{d V_{d c}^{2}}{d t}=\frac{2}{C}\left(P_{f}-P_{r}\right)
\end{array}\right.
$$

\subsection{Model of RL filter:}

The currents passed between the converter and the grid is imposed by the coils constituting the low pass filter [9]-[25]. The three-phase voltages across the filter are:

$$
\left[\begin{array}{l}
v_{f 1} \\
v_{f 2} \\
v_{f 3}
\end{array}\right]=R_{f} \cdot\left[\begin{array}{l}
i_{f 1} \\
i_{f 2} \\
i_{f 3}
\end{array}\right]+L_{f} \frac{d}{d t}\left[\begin{array}{l}
i_{f 1} \\
i_{f 2} \\
i_{f 3}
\end{array}\right]+\left[\begin{array}{l}
v_{s 1} \\
v_{s 2} \\
v_{s 3}
\end{array}\right]
$$

The filter model is given by: 


$$
\begin{aligned}
& \left\{\begin{array}{c}
v_{d f}=-R_{f} \cdot I_{d f}-L_{f} \cdot \frac{d I_{d f}}{d t}+\omega_{s} \cdot L_{f} \cdot I_{q f} \\
v_{q f}=-R_{f} \cdot I_{q f}-L_{f} \cdot \frac{d I_{q f}}{d t}-\omega_{s} \cdot L_{f} \cdot I_{d f}+v_{s}
\end{array}\right. \\
& \left\{\begin{array}{l}
P_{f}=V_{d f} \cdot I_{d f}+V_{Q f} \cdot I_{Q f} \\
Q_{f}=V_{d f} \cdot I_{d f}-V_{Q f} \cdot I_{Q f}
\end{array}\right.
\end{aligned}
$$

\section{SLIDING MODE CONTROL STRATEGY}

The advantages of SMC control are significant and multiple, a better precision, a very fast response time low and in particular robustness [10]-[22]. The SMC control is a robust method that has the strength to keep the uncertain systems performance, in various theorical and industrial applications, stable. The SMC controller is designed to systematically take into consideration the stability and the performance problems. This method is divided into three steps:

- Selecting the sliding surface.

- Defining the convergence conditions based on Lyapunov functions.

- Determining the strategy of the control.

\subsection{Sliding surface}

The basic function for choosing the sliding surface is [11]-[24]:

$$
S(x, t)=\left(\frac{d}{d t}+\lambda\right)^{n-1} \cdot e(t)
$$

With,

$e(t):$ the error in the output state $e(t)=x_{\text {ref }}(t)-x(t)$.

$\lambda:$ a positive coefficient.

$n:$ the $n^{t h}$ order system. Where for $n=1, S(x, t)=e(t)$.

\subsection{The convergence conditions:}

The equation of Lyapunov defines the convergence conditions.

$$
S(x) . \dot{S}(x)<0
$$

The validation of this equation, explains that the 2 sizes converge towards the same surface.

\subsection{The controller design:}

The controller structure entails two parts [23]:

$$
u(t)=u_{e q}(t)+u_{N}(t)
$$

$u_{e q}(t)$ equivalent part of the controller, calculate from system behavior $\dot{S}(x)=0$.

$u_{N}(t)$ is used to validate the convergence condition $S(x) \cdot \dot{S}(x)<0$, it is defined by the sign of the surface.

$$
u_{N}(t)=K \operatorname{sgn}(S(x))
$$

where:

$$
\operatorname{sgn}(S(x))=\left\{\begin{array}{cc}
1 & S(x)>0 \\
0 & S(x)=0 \\
-1 & S(x)<0
\end{array}\right.
$$

\section{THE SLIDING MODE APPLIED ON PSGM}

The SMC created based on the mathematical model of the PSGM. For the order system $n=1$, the manifold equations can be presented as [12]:

$$
\left\{\begin{array}{c}
S(\Omega)=e(\Omega)=\Omega_{r e f}-\Omega \\
S\left(I_{d s}\right)=e\left(I_{d s}\right)=I_{d s_{r e f}}-I_{d s} \\
S\left(I_{q s}\right)=e\left(I_{q s}\right)=I_{q s_{r e f}}-I_{q s}
\end{array}\right.
$$




\subsection{The direct stator current controller}

The controller design of the direct current is defined as [13]:

$\dot{S}\left(I_{s d}\right)=\dot{I}_{s d_{r e f}}-\dot{I}_{s d}$

$$
\dot{S}\left(I_{s d}\right)=\dot{I}_{s d_{r e f}}+\frac{R_{S}}{L_{d}} \cdot I_{s d}-p \cdot \Omega \cdot \frac{L_{q}}{L_{d}} \cdot I_{s q}-\frac{1}{L_{d}} V_{s d}
$$

The control voltage $V_{s d_{r e f}}$ is obtained by:

$$
\begin{aligned}
& V_{s d_{r e f}}=V_{s d_{e q}}+V_{s d_{N}} \\
& V_{s d_{e q}}=L_{d}\left[\dot{I}_{s d_{r e f}}+\frac{R_{S}}{L_{d}} \cdot I_{s d}-p \cdot \Omega \cdot \frac{L_{q}}{L_{d}} \cdot I_{s q}\right] \\
& V_{s d_{N}}=K_{d} \operatorname{sgn}\left(S\left(I_{s d}\right)\right) \text { with } K_{d}>0 .
\end{aligned}
$$

\subsection{The Quadrature stator current controller}

The controller design of the quadrature current is defined as following [14]:

$$
\begin{aligned}
& \dot{S}\left(I_{s q}\right)=\dot{I}_{s q_{r e f}}-\dot{I}_{s q} \\
& \dot{S}\left(I_{s q}\right)=\dot{I}_{s q_{r e f}}+\frac{R_{S}}{L_{q}} I_{s q}+p \Omega \frac{L_{d}}{L_{q}} I_{s d}+\frac{p . \Omega}{L_{q}} \Phi_{f}-\frac{1}{L_{q}} V_{s q}
\end{aligned}
$$

The control voltage $V_{s q_{r e f}}$ is obtained by:

$$
\begin{aligned}
& V_{s q_{r e f}}=V_{s q_{e q}}+V_{s q_{N}} \\
& V_{s q_{e q}}=L_{q}\left[\dot{I}_{s q_{r e f}}+\frac{R_{S}}{L_{q}} \cdot I_{s q}+p \cdot \Omega \cdot \frac{L_{d}}{L_{q}} \cdot I_{s d}+\frac{p \cdot \Omega}{L_{q}} \cdot \Phi_{f}\right] \\
& V_{s q_{N}}=K_{q} \operatorname{sgn}\left(S\left(I_{s q}\right)\right) \text { with } K_{q}>0 .
\end{aligned}
$$

\subsection{Speed regulator}

The following equations present the sliding surface and its derivative [15]-[26]:

$$
\begin{aligned}
& e(\Omega)=\Omega_{r e f}-\Omega \\
& \dot{S}(\Omega)=\dot{\Omega}_{r e f}-\frac{F}{J} \Omega-\frac{3 p \phi_{f}}{2 J} I_{q s}+\frac{C_{r}}{J}
\end{aligned}
$$

The control voltage $I_{s q_{r e f}}$ is obtained by:

$$
\begin{aligned}
& I_{q s_{r e f}}=I_{q s_{e q}}+I_{q s_{N}} \\
& I_{q s_{e q}}=\frac{2 J}{3 p \phi_{f}}\left[\dot{\Omega}_{r e f}+\frac{F}{J} \Omega+\frac{c_{r}}{J}\right] \\
& I_{q s_{N}}=K_{\Omega} \operatorname{sgn}(S(\Omega)) \text { with } K_{\Omega}>0 .
\end{aligned}
$$

\section{SIMULATION \& RESULTS}

The SMC design of the PMSG based WECS (Figure 4) was simulated under the MATLABSimulink environment. The sampling frequency chosen is $10 \mathrm{kHz}$. 


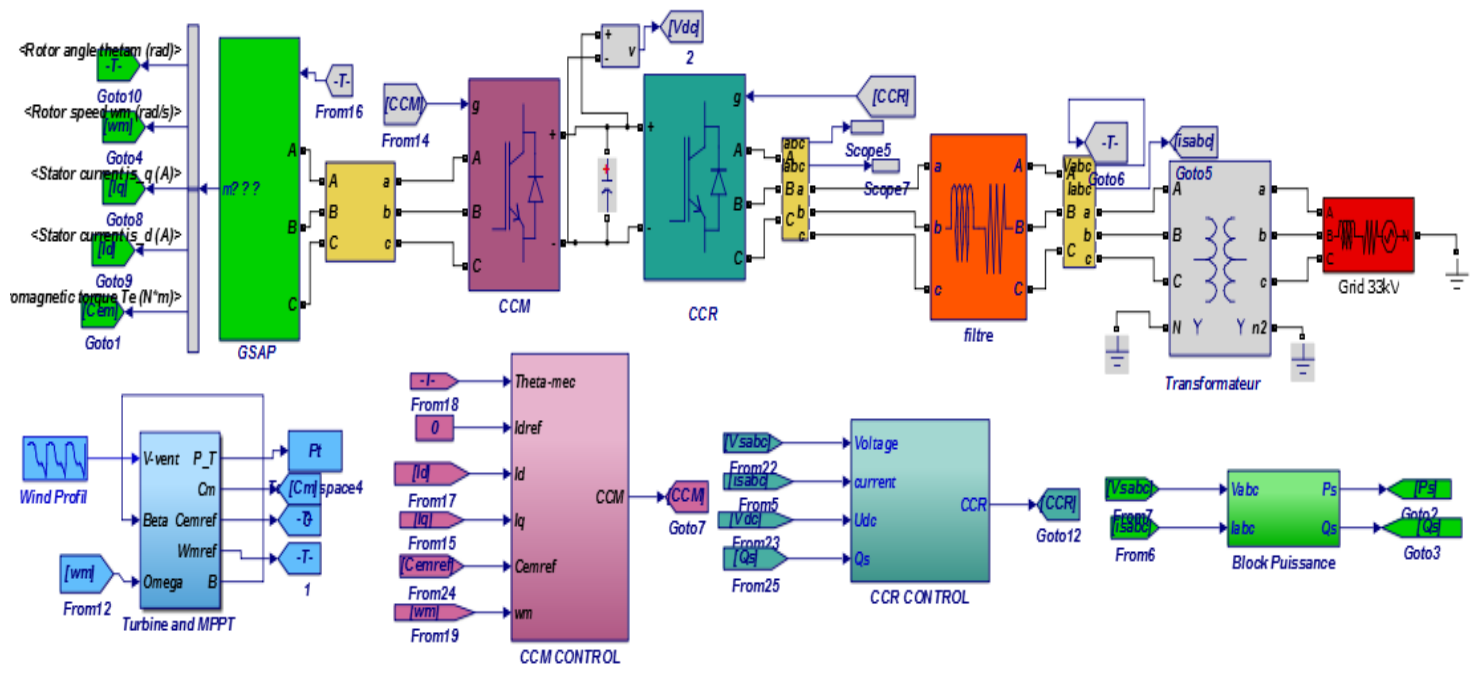

Figure 4. Sliding Mode Control for the WECS in Matlab\&Simulink

In order to approach reality and test the performance of the systems (tracking and robustness), we chose a random wind profile using the MPPT technique. Figure 5 and Figure 6 presents the realization of the SMC block on Matlab simulink, for the regulation of the power Ps and Qs.

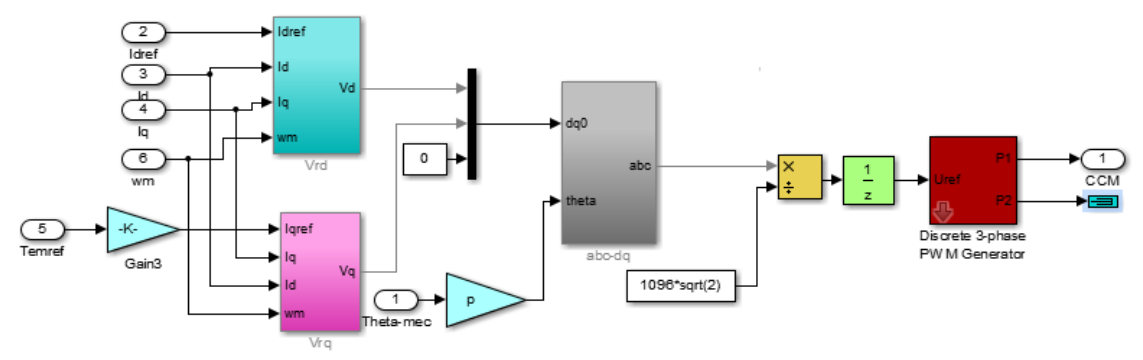

Figure 5. SMC control of the Generator Side Converter (Model Matlab)

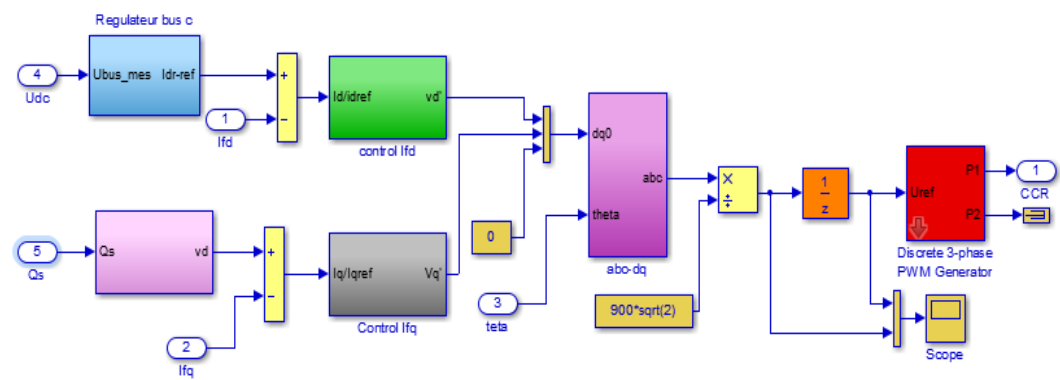

Figure 6. SMC control of the Grid Side Converter (Model Matlab)

\subsection{Tracking test}

The objective of this test is to verify the continued performance of the wind power system for a constant wind speed, by applying the sliding mode control. 


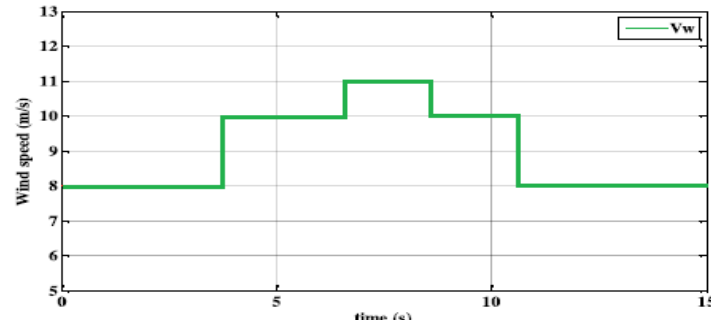

(a)

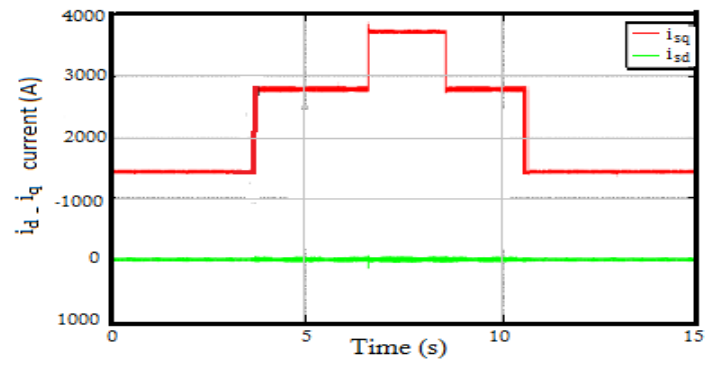

(c)

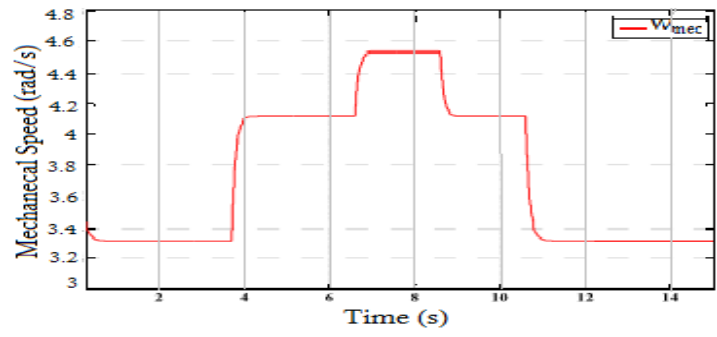

(b)

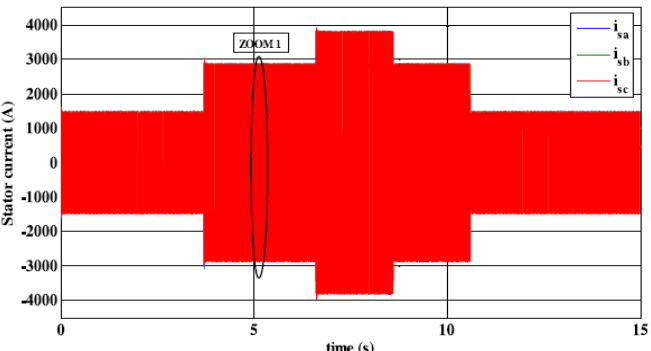

(d)

Figure 7. Follow-up tests, (a) Wind speed reference, (b) Mechanical Speed, (c) d-q stator current, (d) abc stator current

Figure 7(a) shows the wind speed (steps) with which the wind system is attacked. Figure 7(b) shows the evolution of the mechanical speed at the outlet of the turbine, it follows the reference well. The stator currents in the two fields (dq and abc) presented in Figure 7(c) and Figuer 7(d) are of very good quality, with a sinusoidal shape and a THD of less than $5 \%$.

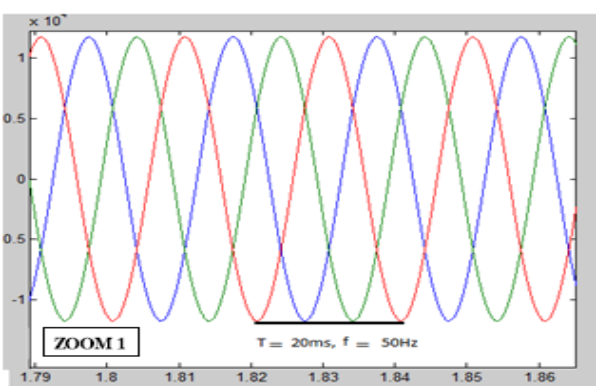

(a)

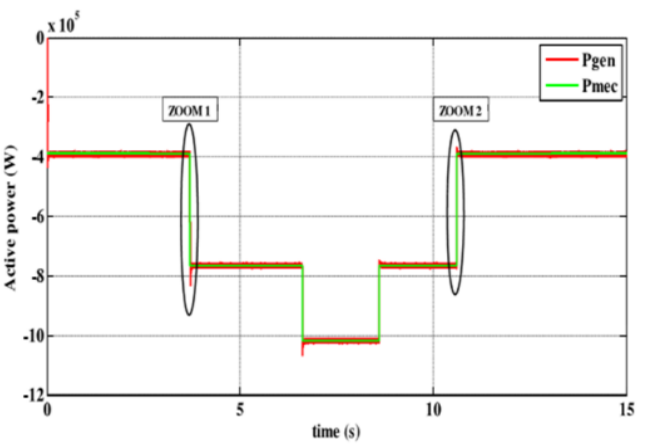

(c)

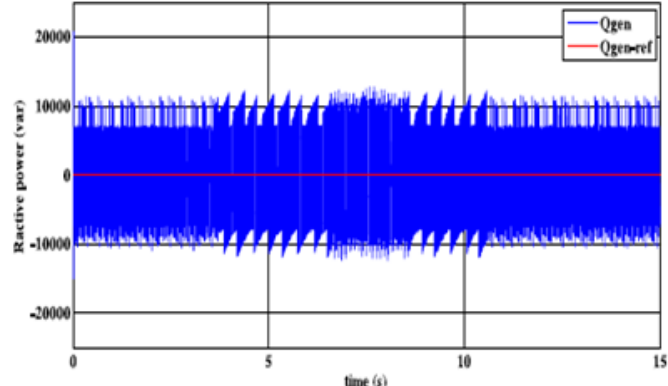

(b)

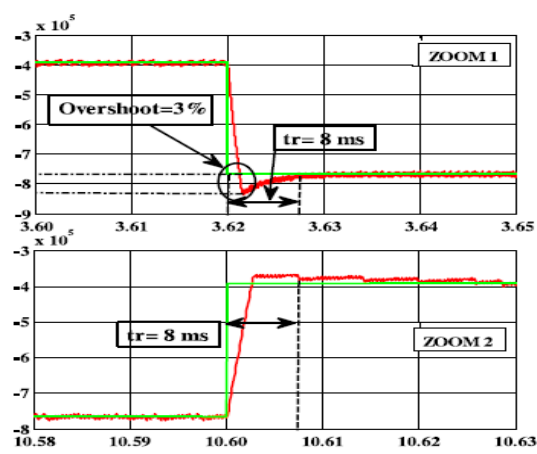

(d)

Figure 8. Results of the SMC control of the GPSM for fixed wind speed, (a) Zoom for abc stator current,

(b) Reactive Power, (c) Active Power, (d) Zoom for Active Power 
The frequency of the current generated by the wind power system at a frequency of $50 \mathrm{~Hz}$, which allows good injection into the electrical network (Figure 8 (a)). The monitoring of the active power Ps and reactive power Qs references of the wind power system is very well done (Figure 8(b) and 8(c)) which validates our approach in this test.

\subsection{Performance for a variable wind speed reference}

Figure 9 shows the reference wind speed, in this section a variable speed is used to check the robustness of the system.

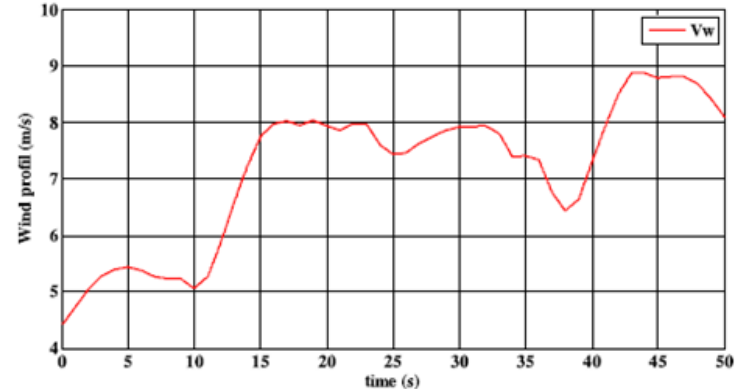

(a)

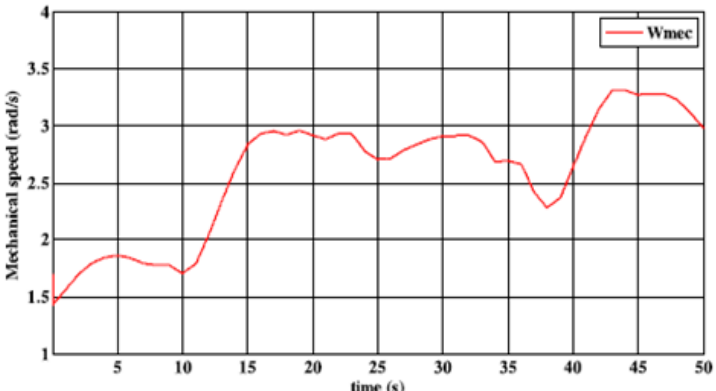

(b)

Figure 9. (a) wind speed reference, (b) Mechanical Speed

Figure. 10 shows the performance of the wind power system during the application of a control by sliding mode. The active and reactive powers follow the refrence well. The stator currents are in good shape and shown in Figure 10(a) and Figure 10(b).

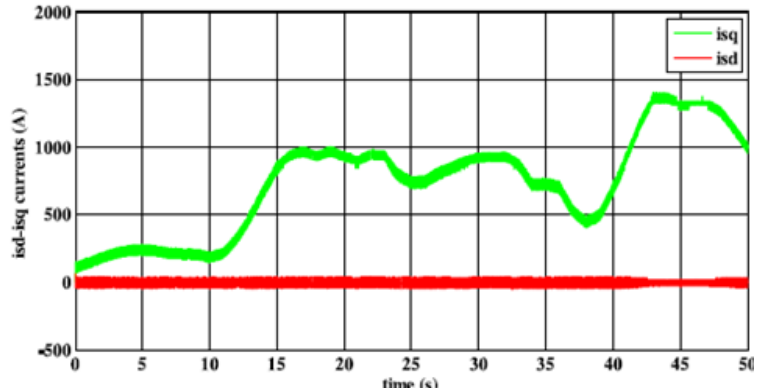

(a)

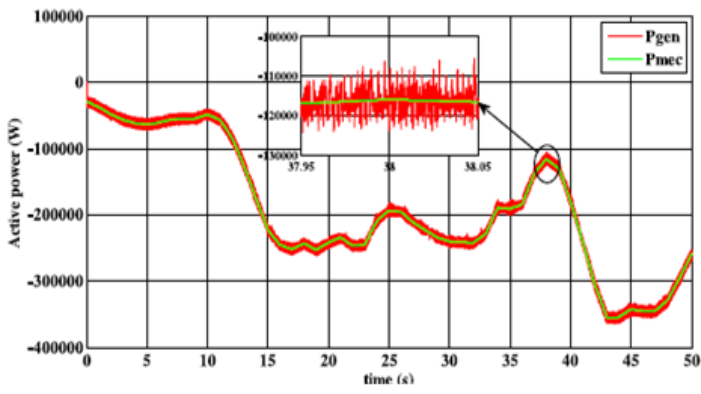

(c)

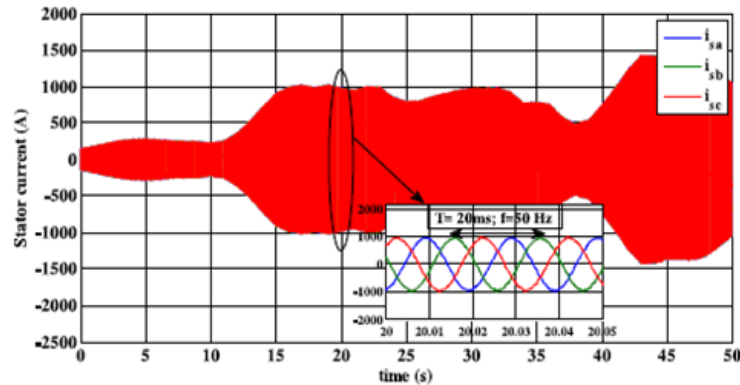

(b)

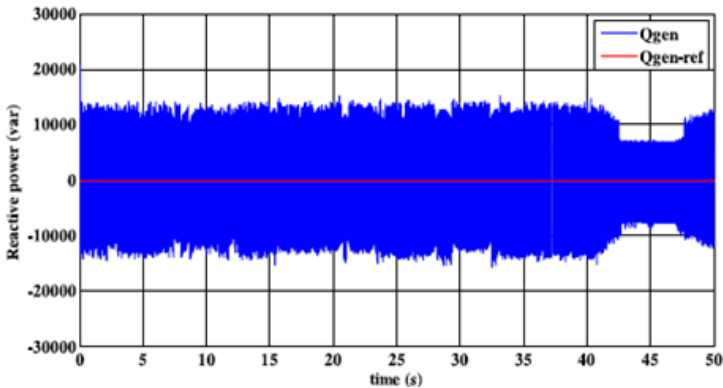

(d)

Figure 10. Results of the control by sliding mode of the GPSM for variable wind speed, (a) d-q stator current, (b) abc stator current, (c) Active Power, (d) Reactive Power 


\section{CONCLUSION}

In this work, we are interested in the control of a wind power system based on GMSM. The use of a control strategy in Sliding Mode which is based on the lyapunov technique is very interesting and the performances obtained are markedly improved. The proposed model has been tested by simulation for a fixed and variable wind speed; tracking and robustness tests have been verified. The wind system performance is very much improved compared to other techniques.

\section{REFERENCES}

[1] Fallahzadeh-Abarghouei, H., Hasanvand, S., Nikoobakht, A., Doostizadeh, M., "Decentralized and hierarchical voltage management of renewable energy resources in distribution smart grid," International Journal of Electrical Power \& Energy Systems. Vol. 100, pp. 117-128, 2018.

[2] D.U. Campos-Delgado, D.R. Espinoza-Trejo, E. Palacios, "Fault-tolerant control in variable speed drives : a survey," IET Electric Power Applications. Vol. 2, No. 2, pp. 121 - 134, March 2008.

[3] Y. El Mourabit, A. Derouich, A. El ghzizal, J. Bouchnaif, N. El ouanjli, O. Zamzoum, K. Mezioui, B. Bossoufi, "Implementation and validation of backstepping control for PMSG wind turbine using dSPACE controller board" Energy Report Journal, pp 807-821, Vol. 5. September 2019.

[4] D. Seyoum, C. Grantham, "Terminal Voltage Control of a Wind Turbine Driven Isolated Induction Generator using Stator Oriented Field Control," IEEE Transactions on Industry Applications, pp. 846-852, September 2003.

[5] B. Bossoufi, M. Karim, A. Lagrioui, M. Taoussi, A. Derouich "Observer Backstepping control of DFIG-Generators for Wind Turbines Variable-Speed: FPGA-Based Implementation,” Renewable Energy Journal, pp 903-917, Vol. 81. September 2015.

[6] Lund, J.W., Boyd, T.L., "Direct utilization of geothermal energy 2015 worldwide review," Geothermics, Vol. 60, pp. 66-93, 2016.

[7] M. El Mahfoud, B. Bossoufi, N. El Ouanjli, M. Taoussi, A. Derouich, "Comparative Study Between Backstepping Adaptive and Field Oriented Controls for Doubly Fed Induction Motor," European Journal of Electrical Engineering, Vol 22, No 3, pp 209-221, June 2020.

[8] Dragomir, G., Şerban, A., Năstase, G., Brezeanu, A.I., "Wind energy in Romania: A review from 2009 to 2016. Renew,” Sustain. Energy Rev. Vol. 64, pp. 129-143, 2016.

[9] Domínguez, J.A., Dufo-López, R., Yusta-Loyo, J.M., Artal-Sevil, J.S., Bernal- Agustín, J.L., "Design of an electric vehicle fast-charging station with integration of renewable energy and storage systems," International Journal of Electrical Power \& Energy Systems, 105, 46-58, 2019.

[10] H. Alami Aroussi, El. M. Ziani, M. Bouderbala, B. Bossoufi, "Improvement of Direct Torque Control Applied to Doubly Fed Induction Motor Under Variable Speed," International Journal of Power Electronics and Drive System (IJPEDS). Vol. 11, No. 1, pp. 1511-1520, 2020.

[11] Mahela, O.P., Shaik, A.G., "Comprehensive overview of grid interfaced wind energy generation systems," Renew. Sustain. Energy Rev. Vol. 57, pp. 260-281, 2016.

[12] F. El Hammouchi, L. El Menzhi, A. Saad, Y. Ihedrane, B. Bossoufi "Wind turbine doubly-fed asynchronous machine diagnosis defects using stator and rotor currents lissajous curves," International Journal of Power Electronics and Drive System (IJPEDS), Vol. 10, No. 2, pp. 961-971, 2019.

[13] M. Bouderbala, B. Bossoufi, A. Lagrioui, M. Taoussi, H. Alami Aroussi, Y. Ihedrane, "Direct and indirect vector control of a doubly fed induction generator based in a wind energy conversion system", International Journal of Electrical and Computer Engineering (IJPEDS), Vol. 9, No. 3, pp. 1531-1540, 2018.

[14] B. Beltran, T. Ahmed-Ali and M. E. H. Benbouzid, "High-Order Sliding-Mode Control of Variable-Speed Wind Turbines," IEEE Transactions on Industrial Electronics, vol. 56, no. 9, pp. 3314-3321, 2009.

[15] M. Taoussi, M. Karim, B. Bossoufi, D. Hammoumi, A. Lagrioui "Speed Variable Adaptive Backstepping Control of the Double-Fed Induction Machine Drive," International Journal of Automation and Control, Vol.10, No.1, pp 12-33, March 2016.

[16] B. Bossoufi, H. Alami Aroussi, El. M. Ziani, A. Lagrioui, A. Derouich "Low-Speed Sensorless Control of DFIG Generators Drive for Wind Turbines System," WSEAS Transactions on Systems and Control, Vol. 9, No.4, pp. 514$525,2014$.

[17] M. Taoussi, M. Karim, B. Bossoufi, D. Hammoumi, A. Lagrioui "Low-Speed Sensorless Backstepping control of for the Double-Fed Induction Machine Generator Drive," Journal of Theoretical and Applied Information Technology, Vol. 74, No.2, pp. 189-199, 2015.

[18] R. Jaiswal, A. Agarwal, V. Agarwal, B. Bossoufi. "Control Strategy of a Solid-State Transformer for the Grid-Side Converter," Recent Advances in Electrical \& Electronic Engineering, Vol. 13, Num 1, pp. 27-35, February 2020.

[19] Y. Ihedrane, C. El Bekkali, B. Bossoufi, M. Bouderbala "Control of Power of a DFIG Generator with MPPT Technique for Wind Turbines Variable Speed", Renewable Energies book Modeling, Identification and Control Methods in Renewable Energy Systems, SPRINGER, pp 105-129, 25 December 2018.

[20] N. El Ouanjli, M. Taoussi, A. Derouich, A. Chebabhi, A. El Ghzizal, B. Bossoufi, "High Performance Direct Torque Control of Doubly Fed Induction Motor using Fuzzy Logic," Gazi University Journal of Science System, Vol. 31, No.2, pp 532-542, May 2018.

[21] M. Taoussi, M. Karim, B. Bossoufi, D. Hammoumi, A. Lagrioui "Low-Speed Sensorless Control for Wind Turbine System," WSEAS Transactions on Systems and Control, Vol.12, No.1, pp. 405-417, 2017. 
[22] N. El Ouanjli, A. Derouich, A. El Ghzizal, Y. El Mourabit, M. Taoussi, B. Bossoufi "Contribution to the Performance Improvement of Doubly Fed Induction Machine Functioning in Motor Mode by the DTC Control" International Journal of Power Electronics and Drive System (IJPEDS), Vol. 8, No. 3, pp 1117-1127, 2017.

[23] B. Bossoufi, S. Ionita, H. Alami Arroussi, M. El Ghamrasni, Y. Ihedrane "Managing voltage drops a variable speed wind turbine connected to the grid," International Journal of Automation and Control, Vol.11, No. 1, January 2017.

[24] Y. Ihedrane, C. El Bekkali, B. Bossoufi, "Power Control of DFIG-Generators for Wind Turbines Variable-Speed" International Journal of Power Electronics and Drive System (IJPEDS), Vol. 8, No. 1, pp 444-453, March 2017.

[25] M. Lamnadi, M. Trihi, B. Bossoufi, A. Boulezhar. "Modeling and Control of a Doubly-Fed Induction Generator for Wind Turbine-Generator Systems" International Journal of Power Electronics and Drive System (IJPEDS), Vol.7, No.3, pp. 973-985 September 2016.

[26] M. Taoussi, M. Karim, B. Bossoufi, D. Hammoumi, A. Lagrioui "Speed Variable Adaptive Backstepping Control of the Double-Fed Induction Machine Drive," International Journal of Automation and Control, Vol.10 No.1, pp. 12-33, 2016. 